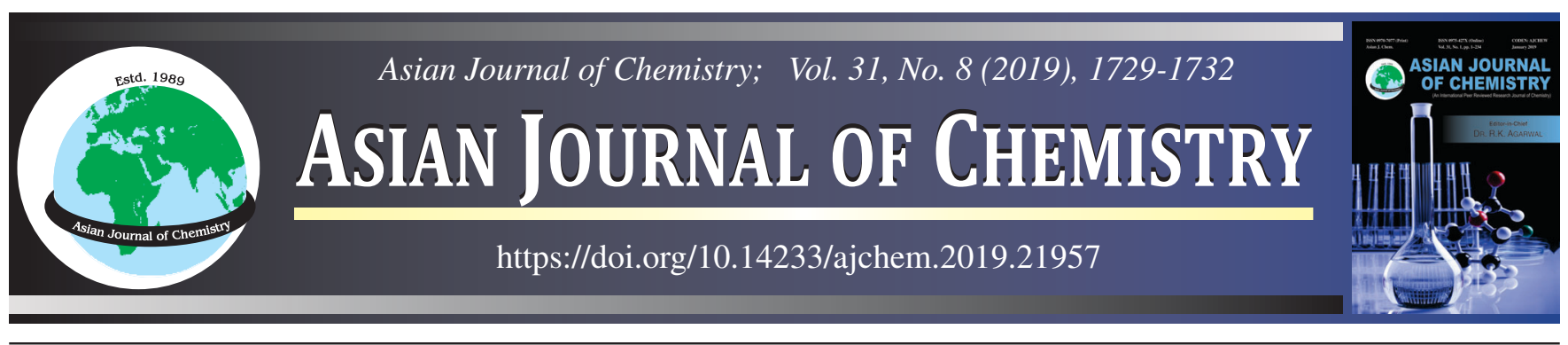

\title{
Structural, Biological and Photocatalytic Properties of Zirconium Oxide Nanoparticles Synthesized by Microwave Assisted Solution Method
}

\author{
S. Vijayalakshmi ${ }^{1,2, \bullet}$, E. Kumar ${ }^{3, * \bullet}$ and S.C. Vella Durai ${ }^{4, \bullet}$
}

${ }^{1}$ Research and Development Centre, Bharathiar University, Coimbatore-641046, India

${ }^{2}$ Department of Physics, Sri S. Ramasamy Naidu Memorial College, Sattur-626203, India

${ }^{3}$ Department of Physics, School of Science, Tamil Nadu Open University, Chennai-600015, India

${ }^{4}$ Department of Physics, J.P. College of Arts and Science, Agarakattu, Tenkasi-627852, India

*Corresponding author: E-mail: kumarnano@gmail.com

Received: 24 January 2019;

Accepted: 16 March 2019;

Published online: 28 June 2019;

AJC-19443

\begin{abstract}
Zirconium dioxide nanoparticles have been synthesized by microwave assisted solution method. The prepared nanoparticle have been characterized by powder X-ray diffraction, scanning electron microscope, Fourier transform infrared spectroscopy, ultraviolet- diffuse reflectance spectra, thermo gravimetric-differential thermal analysis and also evaluated for their antibacterial activity against bacterial strains. XRD pattern showed the prepared $\mathrm{ZrO}_{2}$ nanoparticles having monoclinic structure which shows the average crystalline size around $20 \mathrm{~nm}$. SEM image showed the particles are spherical shape with agglomeration due to the intermolecular attraction for small particle size. From the UV-DRS, the energy band gap has found to be $4.9 \mathrm{eV}$. The results of antibacterial activity showed that the nanocrystalline zirconium dioxide had an important inhibitory activity against Pseudomonas arginosa. Photocatalytic degradation of methylene blue dye in the presence of $\mathrm{ZrO}_{2}$ nanoparticle under sunlight has been investigated at various times. The $75 \%$ of methylene blue dye has been degraded at $140 \mathrm{~min}$ of sunlight irradiation. The photocatalytic activity of catalyst has been high for $40 \mathrm{mg} / 50 \mathrm{~mL}$ sample concentration.
\end{abstract}

Keywords: Nanoparticles, Absorption, Antimicrobial activity, Photocatalytic activity.

\section{INTRODUCTION}

Zirconium oxide $\left(\mathrm{ZrO}_{2}\right)$ is highly used in fighting to bacterial plaque and its high inflexibility makes it fracture resistance. Hence, a predictable antimicrobial agent like $\mathrm{ZrO}_{2}$ nanoparticles can inhibit wide range of microorganism can be exploited to address this issue. Zirconia ceramics has been increasingly used as implant biomaterials [1]. The zirconia has excellent physical, optical behaviour, electrical conductivity, mechanical and thermal properties, so it has been made a good choice and structural properties [2], dental crowns [3], femoral heads for total hip replacement [4], electrolyte for solid oxide fuel cell [5], catalytic applications [6] has used. Nanostructure materials exhibited unique physio-chemical properties that are unnoticed in conventional bulk materials. Nanosized $\mathrm{ZrO}_{2}$ having much better chemical and physical properties compared to normal $\mathrm{ZrO}_{2}$. The important advantage of inorganic antimicrobial agents is improved safety and stability compared with organic microbial agents. Currently, nanoparticles are growingly accepted for their utility in biological applications including nanomedicines [7]. Nanoparticles assist cell imaging, drug delivery and cancer therapy is nice medicals application of nanoscience. Even though their potential biomedical applications, few studies have reported on the role of zirconia nanoparticles as dental imaging and bone tissue. This material also works an anti-infection applications. The steady increase in the antimicrobial resistance of micro organism represents a great public health apprehension. So for this reason, present study has made an attempt to point out the antimicrobial properties of $\mathrm{ZrO}_{2}$ nanoparticles were determined using the agar diffusion method. There are many synthesis routes have been employed to obtain nanosized zirconium dioxide particles like co-precipitation [8], solid state reaction [9], hydrothermal method [10], sol-gel [11] and microwave assisted solution method [12]. Among this microwave

This is an open access journal, and articles are distributed under the terms of the Attribution 4.0 International (CC BY 4.0) License. This license lets others distribute, remix, tweak, and build upon your work, even commercially, as long as they credit the author for the original creation. You must give appropriate credit, provide a link to the license, and indicate if changes were made. 
assisted solution technique of nanomaterials has attracted in last few years, because of its many applications, such as unique synthetic, short processing durations, uniformly, rapid heating, and minimum power necessities [13]. In this article, prepared $\mathrm{ZrO}_{2}$ nanoparticles are examined by XRD, FTIR, UV, SEM, TG-DTA and antibacterial activity.

\section{EXPERIMENTAL}

Zirconium oxychloride $\left(\mathrm{ZrOCl}_{2} \cdot 8 \mathrm{H}_{2} \mathrm{O}\right)$ and $\mathrm{NaOH}$ were used for the preparation of zirconium oxide nanoparticles. In the present work, $8.6 \mathrm{~g}$ of zirconium oxychloride was added with deionized water and stirred for homogeneous solution, during stirring $\mathrm{NaOH}$ solution was added till $\mathrm{pH}$ value becomes 12. After that white sol has been formed. This solution kept at microwave oven with minimum temperature for $6 \mathrm{~min}$. The prepared powder filtered with deionized water and dried at 50 ${ }^{\circ} \mathrm{C}$ for $1 \mathrm{~h}$. This powder was calcinated at $600{ }^{\circ} \mathrm{C}$ for $4 \mathrm{~h}$.

Detection method: XRD patterns of the samples were investigated using X-ray diffractometer (X-PERT PRO PANlytical, Netherland) to study the crystalline nature. $\mathrm{CuK} \alpha$ radiation of wavelength $\lambda=1.5406 \AA$ was used as a diffraction source and with the step size of 0.050 from the diffraction range $10-80^{\circ}$. The morphology behavior of prepared samples were studied by SEM analyzing method (scanning electron microscope) (Hitachi SEM S 2400 device) with an operating voltage $20 \mathrm{kV}$. The FTIR spectra was recorded in the range of $4000-400 \mathrm{~cm}^{-1}$ using a Shimadzu 8400S FTIR spectrometer. The materials are finely dispersed in $\mathrm{KBr}$ using an agate mortar and then pressed into circular disc of $10 \mathrm{~mm}$ diameter and $0.5 \mathrm{~mm}$ thickness at a pressure of $250 \mathrm{MPa}$. These pellets are dried with IR light source. The optical property of prepared nanoparticles was recorded using JASCO UV visible spectrometer. Thermal stability of prepared nanoparticles was recorded using TG-DTA. $\mathrm{ZrO} 2$ nanoparticles has been evaluated with well disc-diffusion method and it was used to confirm the antimicrobial activity. The experiment was conducted against reference gram positive and gram negative bacteria procured from MTCC (Microbial Type Culture Collection). $6 \mathrm{~mm}$ thick sterile discs were placed suitably on petridishes. As a final point, different concentrations of zirconium oxide nanoparticles (20 and $100 \mu \mathrm{g} / \mathrm{mL}$ ) were loaded on each disc. All the plates were incubated at $37^{\circ} \mathrm{C}$ for $24 \mathrm{~h}$ and the respective inhibition zones were calculated.

\section{RESULTS AND DISCUSSION}

XRD analysis: Zirconium oxide $\left(\mathrm{ZrO}_{2}\right)$ was synthesized by microwave assisted solution technique. The powder XRD pattern of the prepared $\mathrm{ZrO}_{2}$ nanoparticles is shown in Fig. 1 which shows a strong diffraction peaks along $28.28^{\circ}, 24.16^{\circ}$, $0.32^{\circ}, 34.2^{\circ}, 35.4^{\circ}, 50.19^{\circ}, 40.9^{\circ}, 45.6^{\circ}, 60.3^{\circ}$ and $65.8^{\circ}$ with (h k l) values. The $\mathrm{ZrO}_{2}$ nanoparticles show a tetragonal phase from diffraction peaks [14] at $30.32^{\circ}, 34.2^{\circ}, 50.19^{\circ}$ and $60.3^{\circ}$. From Fig. 1, the diffraction bands were confirmed by crystalline nature. The crystalline nature was confirmed to peaks at (001), (011), (111), (020), (002), (120), (201), (202), (022), (311), (203), (113) and (132). The indexed peaks are confirmed by monoclinic structure [15] at (002), (202), (022), (311) and (113). These both structures were confirmed by SEM images. The broad diffraction bands shows the prepared samples are

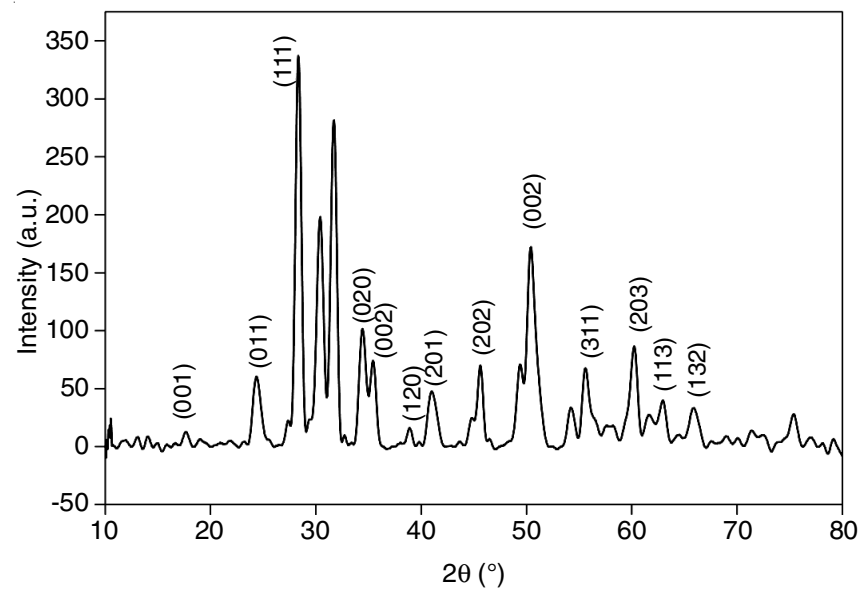

Fig. 1. XRD pattern of $\mathrm{ZrO}_{2}$ nanoparticles

nanosized. The $\mathrm{ZrO}_{2}$ nanoparticle grain size was found as around $35 \mathrm{~nm}$. The grain size calculated formula is given below [16]:

$$
\mathrm{D}=0.9 \lambda / \beta \cos \theta
$$

where $\lambda$ is incident X-ray wavelength, $\lambda$ is FWHM and $\theta$ is diffraction angle. The average grain sizes of $\mathrm{ZrO}_{2}$ nanoparticles were calculated, from the diffraction bands. Finally, XRD pattern was confirmed the crystalline behaviour and also confirmed particles size of $\mathrm{ZrO}_{2}$.

FTIR analysis: The chemical structures and functional group of $\mathrm{ZrO}_{2}$ nanoparticles are characterized by FTIR spectroscopy. Fig. 2 shows the FTIR spectrum of the prepared sample. The weak peaks in $3500-3000 \mathrm{~cm}^{-1}$ region corresponds to the stretching vibrations of $\mathrm{O}-\mathrm{H}$ on surface of $\mathrm{ZrO}_{2}$ nanoparticle, while the peaks at 751 and $577 \mathrm{~cm}^{-1} \mathrm{Zr}-\mathrm{O}_{2}-\mathrm{Zr}$ asymmetric and $\mathrm{Zr}-\mathrm{O}$ stretching modes respectively, confirms the formation of $\mathrm{ZrO}_{2}$ phases [17]. Weak bands observed at 1642 and 3336 $\mathrm{cm}^{-1}$ are explained the stretching and bending vibrations of $\mathrm{O}-\mathrm{H}$ bands, which represents that water molecules are absorbed. The band at $1339 \mathrm{~cm}^{-1}$ is confirmed for the absorption of non-bridged $\mathrm{OH}$ groups. The very sharp peaks $751 \mathrm{~cm}^{-1}$ is occurred due to the characteristic of $\mathrm{m}-\mathrm{ZrO}$.

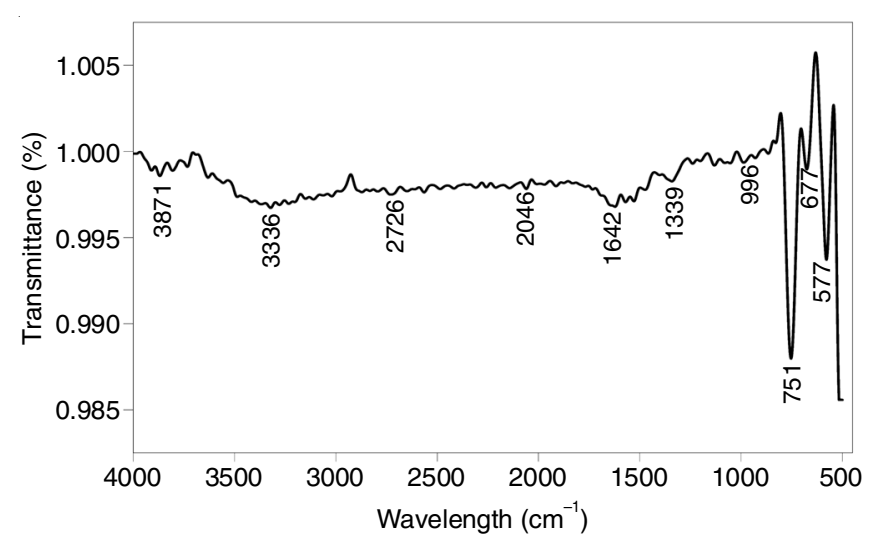

Fig. 2. FTIR spectra of $\mathrm{ZrO}_{2}$ nanoparticles

SEM analysis: Fig. 3 shows the SEM image of prepared sample. The morphology of prepared $\mathrm{ZrO}_{2}$ nanoparticles showed that particles are crystalline nature and looks like stony structure due to the high degree of agglomeration. Agglomeration occurred because of appropriate intermolecular attraction present between 


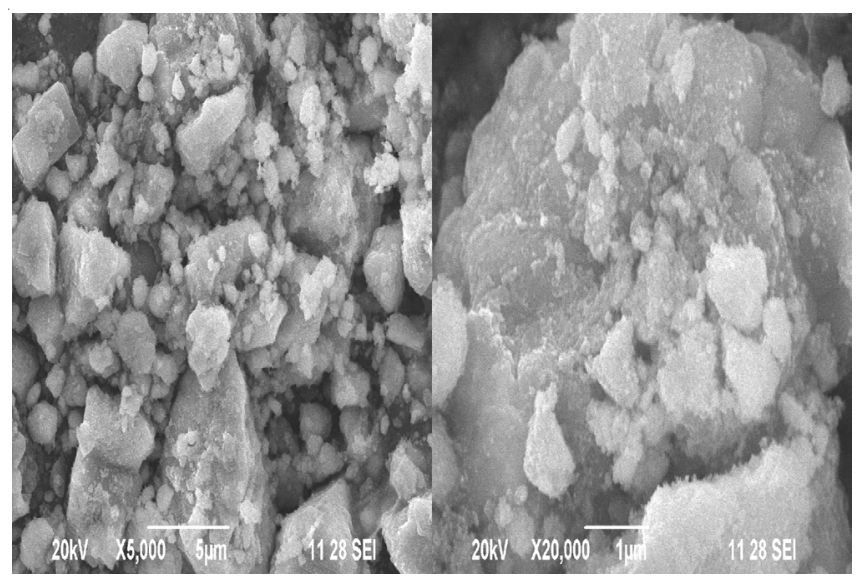

Fig. 3. SEM image of $\mathrm{ZrO}_{2}$ nanoparticles

the prepared nanoparticles. The particles are confirmed as a randomly spherical shape from the image. From the SEM images, the particles size is found to be around 32 to $38 \mathrm{~nm}$. This size was confirmed to support the XRD analysis.

UV-DRS analysis: Figs. 4 and 5 show the UV-DRS spectra of prepared $\mathrm{ZrO}_{2}$ nanoparticles. The optical band gap energy for the prepared $\mathrm{ZrO}_{2}$ sample was determined from diffuse reflectance spectra using Kubelka-Munk equation:

$$
\left[\left(\mathrm{R}_{\infty}\right) \cdot \mathrm{h} \gamma^{2}\right]=\mathrm{A}\left(\mathrm{h} \gamma-\mathrm{E}_{\mathrm{g}}\right)
$$

where $\mathrm{F}\left(\mathrm{R}_{\infty}\right)$ is the Kubelka-Munk function or reemission parameter, $h \gamma$ is the energy of incident photon, $R_{\infty}$ is the diffuse reflectance that is obtained from $R_{\infty}=R_{\text {sample }} / R_{\text {standard }}$ and $A$ is a constant. The $\left[\left(\mathrm{R}_{\infty}\right) . \mathrm{h} \gamma^{2}\right]$ versus $\mathrm{h} \gamma$ was plotted for the prepared sample as shown in Fig. 4. Straight line was drawn to fit the experimental curve and extended to cut off the $h \gamma$ axis, optical band gap energy value has been determined of $\mathrm{ZrO}_{2}$ nanoparticles. From Fig. 4, the optical band gap of prepared $\mathrm{ZrO}_{2}$ nanoparticle has been found to be $4.9 \mathrm{eV}$. The change in absorbance value of dye solution was measured by UV visible absorption spectroscopy. The absorption bands at $665 \mathrm{~nm}$ arise from chromophone in methylene blue [18]. The intensity of absorption bands became weaker as the ultraviolet irradiation time increases; it may be due to the breaking of chromophore in dye by the photocatalytic activity of $\mathrm{ZrO}_{2}$ nanoparticles. The degradation of methylene blue dye with $\mathrm{ZrO}_{2}$ catalyst in the dark and sunlight irradiation can be investigated. The initial

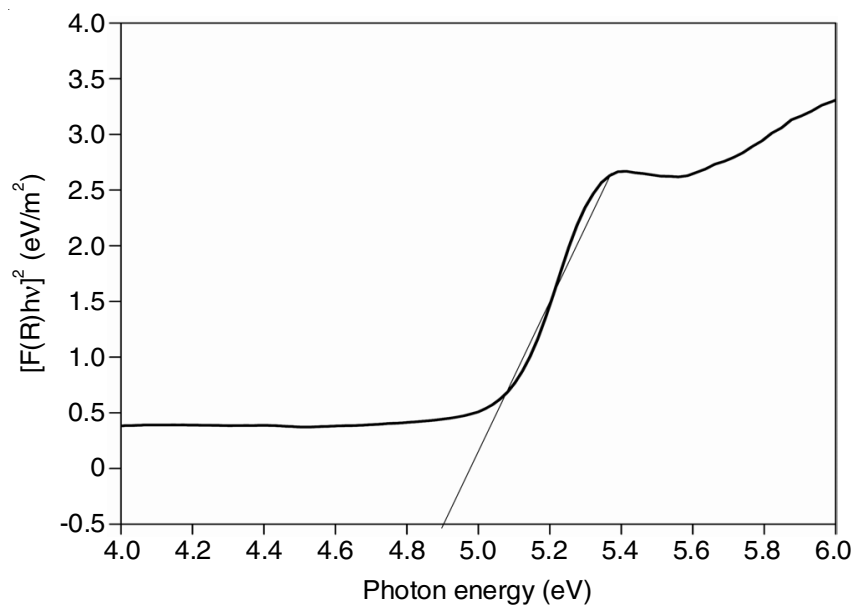

Fig. 4. Band gap energy of $\mathrm{ZrO}_{2}$ nanoparticles

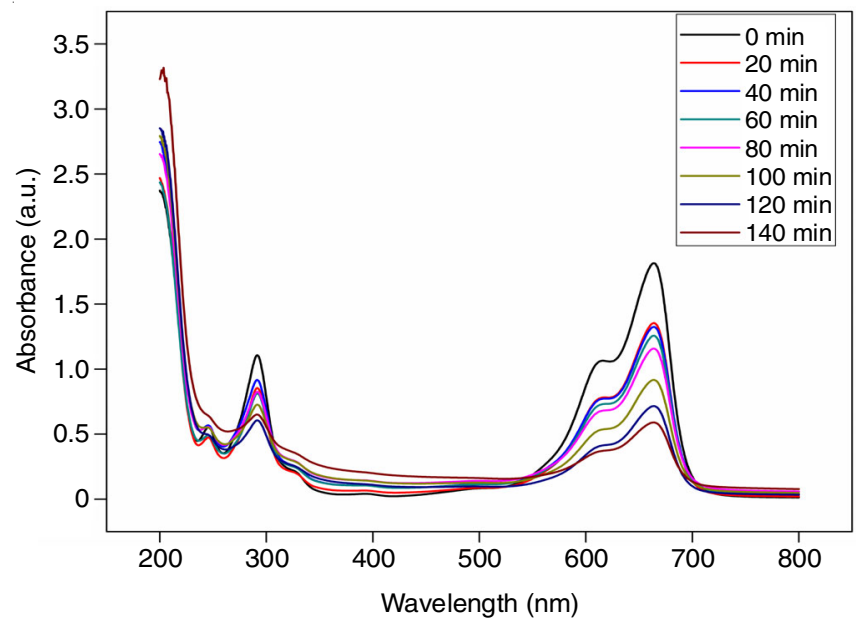

Fig. 5. UV absorption spectra of methylene blue dye by $\mathrm{ZrO}_{2}$ photo catalysis under sunlight

dye concentration on the percentage degradation of dye is shown in Fig. 5. The dye concentration varies from 10 to 50 $\mathrm{mg} / \mathrm{L}$. The degradation increases from 10 to $20 \mathrm{mg} / \mathrm{L}$ then decreases. The dye degradation values are higher at initial concentration of $20 \mathrm{mg} / \mathrm{L}$, it showed that the presence of enough dye molecules when it was compared to $\mathrm{OH}$ radicals for the degradation of dye. A similar result has been obtained by Priyanka and Srivastava [19]. The photocatalytic activity of catalyst has been high for $40 \mathrm{mg} / 50 \mathrm{~mL}$ concentration. The $\mathrm{ZrO}_{2}$ nanoparticles are confirmed the behaviour of catalyst.

TG/DTA analysis: Thermal properties of $\mathrm{ZrO}_{2}$ nanoparticles were characterized using TG/DTA technique. From Fig. 6, $\mathrm{ZrO}_{2}$ nanoprticles have one step weight loss in the temperature range between 10 to $800{ }^{\circ} \mathrm{C}$ and it weight loss occurred due to the reason of impurities in unstable and water losses.

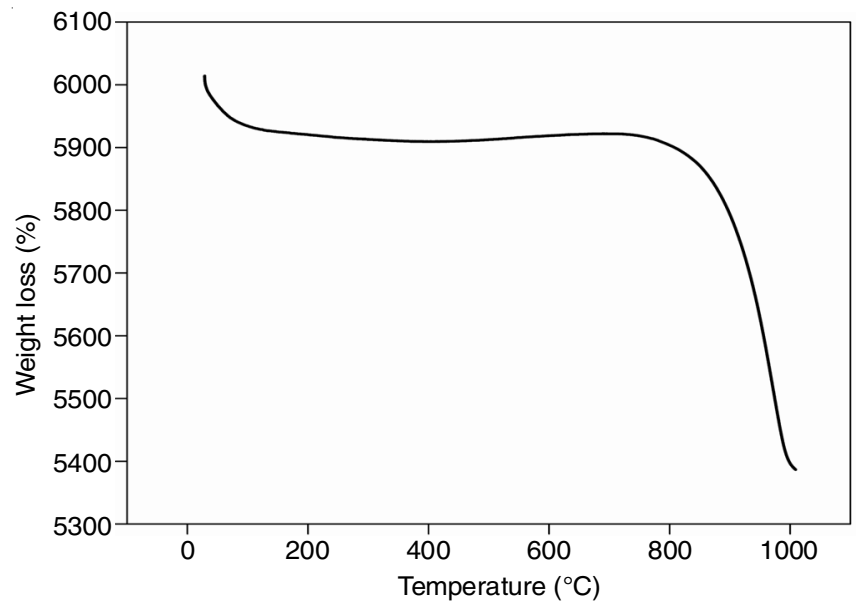

Fig. 6. TG/DTA thermograms of $\mathrm{ZrO}_{2}$ nanoparticles

Antimicrobial activity: The antimicrobial activity of $\mathrm{ZrO}_{2}$ was investigate against gram negative bacteria (Pseudomonas aeruginosa and Escherichia coli) and gram positive bacteria (Staphylococcus aureus and Bacillus subtilis), respectively. The prepared $\mathrm{ZrO}_{2}$ nanoparticles showed a good inhibitory action against $P$ seudomonas aeruginosa (inhibition zone size of $10 \mathrm{~mm}$ ) at $100 \mu \mathrm{g} / \mathrm{mL}$ compared to other bacteria due to the negatively charged, $P$. aeruginosa cell wall readily attracting 
positively charged $\mathrm{ZrO}_{2}$ and in that way inhibiting microbial actions. In addition, $\mathrm{ZrO}_{2}$ nanoparticles were directly proportional to their inhibitory actions beside the tested microorganism. $\mathrm{ZrO}_{2}$ nanoparticles have confirmed that they have possible biomedical applications.

The zeta potential of nanoparticles give an idea about the stability in the medium as it is dispersed in the nanoparticles, this case are suspended in distilled millipore water. If the potential exist in the +30 to $-30 \mathrm{mV}$ range, the particles in the mentioned range concluded that they are not aggregating and stable in the conditions in which they are to be used. Finally, it is confirmed that prepared $\mathrm{ZrO}_{2}$ nanoparticles are more stable and have antimicrobial activity.

\section{Conclusion}

Zirconium oxide nanoparticles were synthesized by microwave assisted solution method. The prepared nanoparticle has monoclinic structure which is confirmed by XRD study. The particle size can be calculated as $35 \mathrm{~nm}$ using Debye-Scherrer equation. SEM images showed the prepared $\mathrm{ZrO}_{2}$ nanoparticle has high degree of agglomeration due to the small size and intermolecular attraction between them. FTIR study confirmed the chemical composition and functional groups present in the prepared sample. The energy band gap value of the prepared sample has found to be $4.9 \mathrm{eV}$ using Kubelka-Munk equation. From the TG/DTA analysis, it is concluded that prepared $\mathrm{ZrO}_{2}$ nanoparticles having high thermal stability. $\mathrm{ZrO}_{2}$ nanoparticles have been important inhibitory activity for gram negative rod like Pseudomonas aruginosa. Photocatalytic degrdation of methylene blue dye in the presence of $\mathrm{ZrO}_{2}$ nanoparticles under sunlight has been investigated at various times. The $75 \%$ of methylene blue dye has been degraded at $140 \mathrm{~min}$ of sunlight irradiation. The photocatalytic activity of catalyst has been high for $40 \mathrm{mg} / 50 \mathrm{~mL}$ sample concentration.

\section{ACKNOWLEDGEMENTS}

The authors are thankful to the authorities of Tamil Nadu Open University, Chennai and Bharathiyar University, Coimbatore, India for providing the necessary research facilities.

\section{CONFLICT OF INTEREST}

The authors declare that there is no conflict of interests regarding the publication of this article.

\section{REFERENCES}

1. C. Piconi and G. Maccauro, Biomaterials, 20, 1 (1999); https://doi.org/10.1016/S0142-9612(98)00010-6.

2. F. Heshmatpour and R.B. Aghakhanpour, Powder Technol., 205, 193 (2011); https://doi.org/10.1016/j.powtec.2010.09.011.

3. C. Oetzel and R. Clasen, J. Mater. Sci., 41, 8130 (2006); https://doi.org/10.1007/s10853-006-0621-7.

4. E.S. Elshazly, S.M. Elhout and E.S. Ali, J. Mater. Sci. Technol., 27, 332 (2011); https://doi.org/10.1016/S1005-0302(11)60070-4.

5. J. Luo, R. Ball and R. Stevens, J. Mater. Sci., 39, 235 (2004); https://doi.org/10.1023/B:JMSC.0000007749.72739.bb.

6. E. Krumov, J. Dikova, K. Starbova, D. Popov, V. Blaskov, K. Kolev and L.D. Laude, J. Mater. Sci. Mater. Electron., 14, 759 (2003); https://doi.org/10.1023/A:1026176431171.

7. M. Premanathan, K. Karthikeyan, K. Jeyasubramanian and G. Manivannan, Nanomedicine, 7, 184 (2011); https://doi.org/10.1016/j.nano.2010.10.001.

8. M.-C. Wang, W.-L. Li, C.-W. Cheng, K.-M. Chang, Y.-F. Chen and C.-S. Hsie, Mater. Chem. Phys., 123, 203 (2010); https://doi.org/10.1016/j.matchemphys.2010.03.083.

9. C.J. Dalmaschio, V.R. Mastelaro, P. Nascente, J. Bettini, J.L. Zotin, E. Longo and E.R. Leite, J. Colloid Interface Sci., 343, 256 (2010); https://doi.org/10.1016/j.jcis.2009.11.027.

10. E.A. Trusova, A.A. Khrushcheva and K.V. Vokhmintcev, J. Eur. Ceram. Soc., 32, 1977 (2012); https://doi.org/10.1016/j.jeurceramsoc.2011.11.006.

11. B. Tyagi, K. Sidhpuria, B. Shaik and R.V. Jasra, Ind. Eng. Chem. Res., 45, 8643 (2006); https://doi.org/10.1021/ie060519p.

12. S.C. Vella Durai, L. Guru Prasad, E. Kumar, D. Muthuraj and V.B. Jothy, Int. J. Res. Advent Technol., 6, 1531 (2018).

13. S. Shukla and S. Seal, Rev. Adv. Mater. Sci., 5, 117 (2003).

14. M.R.H. Siddiqui, A.I. Al-Wassil, A.M. Al-Otaibi and R.M. Mahfouz, Mater. Res., 15, 986 (2012); https://doi.org/10.1590/S1516-14392012005000128.

15. A.S. Keiteb, E. Saion, A. Zakaria and N. Soltani, J. Nanomater, 2016, 1913609 (2016); https://doi.org/10.1155/2016/1913609.

16. E. Kumar, P. Selvarajan and D. Muthuraj, Mater. Res., 16, 269 (2013); https://doi.org/10.1590/S1516-14392013005000021.

17. H.R. Sahu and G.R. Rao, Bull. Mater. Sci., 23, 349 (2000); https://doi.org/10.1007/BF02708383.

18. T. Zhang, T. Oyama, A. Aoshima, H. Hidaka, J. Zhao and N. Serpone, Photochem. Photobiol. A, 140, 163 (2001); https://doi.org/10.1016/S1010-6030(01)00398-7.

19. V. Priyanka and V.C. Srivastava, Ind. Eng. Chem. Res., 52, 17790 (2013); https://doi.org/10.1021/ie401973r. 